\title{
HABILIDADES MOTORAS E TIPOS DE PRÁTICA: UMA REFLEXÃO VISANDO O APRIMORAMENTO E CONSCIENTIZAÇÃO DO MOVIMENTO NA PRÁTICA PIANÍSTICA ${ }^{1}$
}

\author{
Felipe Moretti Rodrigues ${ }^{2}$; Maria Bernardete Castelan Póvoas ${ }^{3}$ \\ Grupo de Pesquisa: Processos Músico- Instrumentais \\ felipemoretti_@hotmail.com bernardete@brturbo.com.br
}

\section{Resumo}

Este estudo foi parte integrante do projeto de pesquisa intitulado Ação Pianística $e$ Coordenação Motora: Relações Interdisciplinares. O projeto teve como proposta uma discussão interdisciplinar com o objetivo de relacionar aspectos da técnica pianística com argumentos de áreas que estudam a ação motora. Neste trabalho são abordados, mais especificamente, dois temas: habilidades motoras e tipos de prática. Como objetivo, buscou-se argumentos para orientação de uma prática mais eficiente do movimento corporal ao piano e conseqüente auxilio no aprendizado músico-instrumental.

Palavras Chave: coordenação motora, habilidades motoras, tipo de prática, interdisciplinaridade.

\section{INTRODUÇÃO}

A técnica ao piano é essencial na interpretação e desempenho musical. Este desempenho conta com domínio de conhecimentos, experiência e vivência musicais. No que diz respeito ao desempenho pianístico, um importante assunto é o domínio dos movimentos ao piano, fundamental para a realização prática dos conhecimentos teóricos. Existem estudantes de piano com muita musicalidade que encontram verdadeiras barreiras à evolução de seus estudos, por falta de agilidade ou precisão dos próprios movimentos. A técnica, portanto, é um aspecto da construção interpretativa que merece, sem dúvidas, a atenção dos musicistas. A técnica pianística engloba diversos fatores como o estudo de escalas, acordes, independência dos dedos, diferentes tipos de toque, ou seja, estudos de otimização da técnica junto ao instrumento musical, visando uma sonoridade ideal. Tal estudo necessita, portanto, de conhecimento e consciência da atividade motora própria dos membros envolvidos nesta

\footnotetext{
${ }^{1}$ Vinculado ao Projeto de Pesquisa CEART-UDESC: Ação Pianística e Coordenação Motora: Relações Interdisciplinares.

${ }^{2}$ Bolsista de Pesquisa PROBIC - UDESC, aluno do curso de Bacharelado em Piano CEART/UDESC.

${ }^{3}$ Professora Dra. do Departamento de Música CEART/UDESC. Coordenadora do projeto.atividade.

(RICHERME, 1996, p.11-16). Estudar técnica pianística é, portanto, estudar a melhor maneira de
} 
realizar movimentos ao piano.

A ação pianística exige do musicista a realização de movimentos complexos que necessitam ser feitos de maneira harmoniosa e consciente a fim de que este despenda o menor gasto de energia possível, na busca de um alto desempenho instrumental. Para Póvoas (2007) esta economia de energia se faz no planejamento prévio da execução instrumental, onde o instrumentista precisa estudar os movimentos apropriados na realização do texto musical. $\mathrm{O}$ musicista necessita também, estudar maneiras de otimização do aprendizado, a fim de aproveitar melhor seu tempo de estudo. Para tanto, discutir sobre habilidades motoras e tipos de práticas torna-se fundamental na construção de uma compreensão maior do que é o desempenho músico- instrumental.

\section{MÉTODOS}

A pesquisa consiste no levantamento bibliográfico que aborda a técnica pianística numa visão interdisciplinar. Desta visão são compreendidos conceitos das mais diversas áreas, como a biomecânica e cinesiologia, contribuindo e expandindo nossa compreensão da técnica pianística e do desempenho músico-instrumental. Tal expansão ocorre, pois analisamos o desempenho musical a partir de uma visão científica do funcionamento dos membros do corpo, do sistema muscular, entre outros. Deste levantamento bibliográfico surge a leitura e reflexão dos temas pesquisados que, posteriormente, são debatidos nas reuniões semanais entre os pesquisadores e a orientadora.

Foi desenvolvido um estudo sobre a classificação das habilidades motoras e os tipos de prática onde foi compreendida a evolução na qualidade e precisão dos movimentos executados pelo ser humano, bem como mecanismos de que este se vale na apreensão do conhecimento. Através das relações interdisciplinares realizadas entre teorias biomecânicas e a prática instrumental, foi possível aplicar à realidade prática do estudo pianístico determinados conceitos que comprovaram sua eficácia. A maneira de organizar o estudo de obras musicais em partes que devem ser estudadas alternadamente é uma prática que a orientadora da pesquisa utiliza com seus alunos e que apresenta resultados satisfatórios.

No estudo pianístico é notável a importância da consciência e plasticidade dos movimentos realizados, bem como o desenvolvimento de técnicas que aprimorem a maneira de memorizar as informações musicais. 


\section{DISCUSSÃO}

\section{- Classificação das habilidades motoras}

Habilidade motora compreende uma tarefa com uma finalidade específica a ser atingida (MAGILL, 2000, p.6-7). Tocar piano, portanto, é uma habilidade que necessita de prática para desenvolver-se. Esta atividade instrumental consiste em uma habilidade motora, haja vista que exige movimentos voluntários do corpo para atingir o objetivo final que é fazer música. Tais movimentos exigem, para sua plena realização, destreza dos segmentos mãos, dedos e braços.

As habilidades motoras, em geral, percorrem um caminho evolutivo. Vão desde a inexperiência até o desempenho habilidoso, sendo muitas vezes atividades do nosso cotidiano como digitar um texto, andar de um lugar a outro ou dirigir um automóvel. A firmeza, estabilidade e desenvoltura dos passos de um adulto, por exemplo, nos fazem perceber que através dos anos há um aprimoramento no desempenho desta atividade, uma vez que os primeiros passos do ser humano são hesitantes. (BARELLA, 1999, p.53). Da mesma maneira, esta realidade é aplicada ao estudo do piano, onde um estudo correto e continuado promove refinamento técnico e sonoro.

Para uma melhor compreensão dos variados tipos de movimento pode-se classificar as habilidades de diversas formas. Em um primeiro momento, com relação aos aspectos musculares do movimento, podemos denominar as habilidades motoras de grossas ou finas. Estes termos fazem referência a tipos diferentes de atividades. As habilidades motoras grossas são aquelas em que as pessoas utilizam os grandes grupos musculares do corpo para produzir uma ação. Fazem partes destas habilidades atividades como pular e caminhar, onde é menor a precisão de refinamento dos movimentos. As habilidades ditas finas são aquelas em que músculos pequenos também são requeridos na ação praticada. Elas exigem um elevado grau de precisão de movimentos e compreendem as atividades de músculos que compõe a movimentação das mãos e dedos, por exemplo. Dentre este tipo de habilidade estão a digitação de um texto, a pintura de uma tela ou abotoar uma camisa. (MAGILL, 2000, p. 8). O desempenho ao piano exige ações que fazem uso tanto dos grandes grupos musculares, quanto dos pequenos. Desde na maneira correta de o pianista sentar no banco do piano, pressionar os pedais, mover os braços até o movimento das mãos e dedos as habilidades finas e grossas estão presentes. 
Segundo Gallahue (2002), o movimento, com base em seus aspectos temporais pode ser classificado como: discreto, em série ou contínuo. Movimento discreto, também chamado de habilidade motora discreta, é aquele que apresenta um começo e fim definidos. Fazem parte desta habilidade atividades como ligar e desligar interruptores de luz, acionar o freio de um carro ou pressionar as teclas de um piano. Cada uma das citadas atividades requer um movimento que começa e termina em posições definidas. O movimento em série, ou habilidade motora serial, compreende o desempenho de um movimento simples e discreto repetido diversas e sucessivas vezes de forma rápida. Um drible no basquete, ou tocar piano podem ser exemplos desta habilidade. Já os movimentos contínuos são compostos por movimentos repetitivos. Podemos citar habilidades como utilizar o "mouse" para desenhar, a natação e o ciclismo como exemplos.

Com relação aos aspectos ambientais do movimento classificamos as tarefas motoras de abertas ou fechadas. Schmidt \& Wrisberg (2001, p. 22-23) explicam que habilidade aberta é aquela "[...] executada em ambiente previsível ou que está em movimento e que requer que as pessoas adaptem seus movimentos em resposta às propriedades dinâmicas do ambiente”. Por não existir um padrão de movimentação e a criança realizar movimentos súbitos em diversas direções, poderíamos dizer que o jogo de "pega- pega" é um exemplo desta atividade aberta. A atividade fechada é "Uma habilidade executada em ambiente previsível ou parado e que permite que as pessoas planejem seus movimentos com antecedência". (SCHMIDT \& WRISBERG, 2001, p.22). Nesta atividade fechada, portanto, quem executa determina quando iniciará a ação, como acontece quando um indivíduo lança uma flecha em um alvo estático.

Podemos classificar também as habilidades motoras pela importância relativa dos elementos motores e cognitivos. Na habilidade motora:

[...] a principal determinante do sucesso do movimento é a qualidade do próprio movimento, com menos ênfase sendo dada aos aspectos perceptivos e de tomada de decisão da tarefa. Por exemplo, um saltador de altura no atletismo sabe exatamente o que fazer (saltar sobre o sarrafo). O desafio para esse indivíduo é produzir movimentos que maximizem a altura vertical. (SCHMIDT \& WRISBERG, 2001, p.20).

A habilidade cognitiva, por outro lado, enfatiza o "saber realizar", ou seja, a estratégia sobre qual movimento realizar. Um exemplo disso é o jogo de xadrez onde "pouco importa se as peças são movidas rápida ou suavemente; o desafio é decidir qual peça mover e 
para onde movê-la a fim de maximizar as chances de vitória". (SCHMIDT \& WRISBERG, 2001, p. 21).

Tocar piano é um exemplo de atividade que requer o uso das habilidades: cognitiva e motora. Tem-se que saber qual movimento e quando realizá-lo além de, efetivamente, produzi-lo. Desta maneira, apresentam-se situações em que uma destas habilidades pode comprometer uma execução. Muitas vezes o pianista pode não estar seguro das notas de determinada passagem musical vacilando, desta forma, no ataque das notas. A habilidade cognitiva, neste caso, interfere na habilidade motora. O inverso também é possível. Não adianta ter grande habilidade técnica ao instrumento se o conteúdo musical não estiver assimilado ou se não se sabe aquilo que deve ser realizado.

\section{- Tipos de Prática}

Existem duas variações de seqüenciamento de tarefas práticas que têm demonstrado bons efeitos sobre a aprendizagem. Estas variações são denominadas: prática em blocos e prática randômica.

A prática em blocos é utilizada por indivíduos que treinam de forma repetida uma mesma tarefa. "Esse procedimento traz uma vantagem de se poder analisar os resultados da tentativa recém executada e tentar aproveitar essa avaliação na melhoria do desempenho na tentativa seguinte". (TEIXEIRA, 2004). A prática em blocos é:

[...] vista durante os exercícios educativos, com indivíduos tentando o mesmo movimento várias vezes, e parece fazer sentido na medida em que ela permite aos aprendizes tempo ininterrupto para se concentrarem no desempenho de cada tarefa, de forma que possam gravar, refinar e se necessário, corrigir uma habilidade antes de partir para a seguinte. (SCHMIDT \& WRISBERG, 2001, p. 247).

Na prática randômica um indivíduo pratica diversas atividades em uma única sessão. Schmidt \& Wrisberg (2001, p. 247) definem que prática randômica é a "seqüência prática na qual os indivíduos realizam uma variedade de diferentes tarefas sem ordem específica, assim evitando, ou minimizando, repetições consecutivas de qualquer tarefa única”. As tarefas, portanto, são alternadas constantemente. A grande diferença entre estas duas práticas é que na prática randômica praticam-se todas as variações de determinada tarefa de forma aleatória, já 
na prática por blocos pratica-se primeiro uma variação da tarefa, para posteriormente dar início a uma segunda tarefa. (SHEA e MORGAN, 1979).

Os primeiros experimentos sobre a eficácia destas duas práticas foram feitos por Shea e Morgan. Estes relataram que a prática randômica, também denominada aleatória, provou ser superior que a em blocos no processo de aprendizagem. (SCHMIDT \& WRISBERG, 2001, p. 247). Corrêa e Pelegrini (1996) também alegam que em geral, as pesquisas produzidas em laboratório, têm demonstrado que a prática em blocos leva a um melhor desempenho na fase de aquisição de determinado conhecimento, porém a prática randômica mostra-se superior ao aprendizado real deste conhecimento. Shea e Graf (1994) sugerem que o desempenho menos habilidoso da atividade randômica na "fase de aquisição" resulta do efeito de interferência as atividades sofrem ao serem alternadas. Schmidt \& Wrisberg (2001, p. 247) sintetizam que:

[...] quando os indivíduos praticam uma grande variedade de movimentos de forma randômica, o desempenho durante a prática é menos produtivo do que o dos indivíduos que praticam movimentos de uma forma em blocos. Entretanto, quando os participantes retomam o desempenho mais tarde, aqueles que originalmente praticaram sob condições randômicas demonstram retenção superior comparada a daqueles que originalmente praticaram sob condições em blocos. Portanto, nos estudos de interferência contextual, descobrimos um desses fenômenos contraintuitivo da aprendizagem humana: desempenho inicial mais pobre (em práticas) leva a uma melhor aprendizagem! Esse padrão de resultados, denominado efeito de interferência contextual, desafia a sabedoria convencional (que a aprendizagem será melhor se os indivíduos forem mais proficientes durante a prática, o que normalmente é o caso durante a prática em blocos).

Pode-se, todavia, utilizar ambas as práticas (em blocos e randômica) na compreensão de uma atividade. Explicam os autores que:

\footnotetext{
Nas primeiras tentativas de uma nova habilidade, os indivíduos no estágio verbalcognitivo de aprendizagem podem se beneficiar mais das condições de prática em blocos do que das condições de prática randômica (SHEA, KOHL \& INDERMILL, 1990), talvez porque eles precisam de uma quantidade de repetições para produzir a ação com sucesso apenas uma vez. Entretanto, assim que os aprendizes adquirem uma aproximação rudimentar do movimento, devem mudar a prática para uma programação randômica. (SCHMIDT \& WRISBER, 2001, p. 253).
}

No piano, a prática randômica pode ser aplicada no estudo dos repertórios que, muitas vezes, são constituídos de obras musical e tecnicamente diferentes e somam um grande número de informações a serem aprendidas. Estudar estas informações de maneira alternada torna o estudo menos cansativo e permite ao estudante prestar maior atenção naquilo que está estu- 
dando. Este tipo de prática minimiza o número de repetições impensadas, favorecendo um estudo direcionado onde o músico está intelectualmente presente na atividade a que se propõe.

\section{CONCLUSÃO}

Compreender como se da o raciocínio e como trabalha o corpo humano é um assunto que estimula pesquisas em diversas áreas do conhecimento. A atividade diária de um pianista utiliza o raciocínio na análise musical, na memorização, mas também na conscientização dos movimentos que o corpo necessita fazer. São inúmeras as estruturas músculo- esqueléticas envolvidas na ação pianística. Desta forma, é fundamental ao pianista conhecer a melhor forma de se aprender novas informações musicais, bem como compreender quais movimentos são mais saudáveis e satisfatórios na realização de sua atividade artística.

Os assuntos discutidos neste trabalho são importantes, portanto, para diferentes áreas do conhecimento, especialmente para a área músico-instrumental. A partir do levantamento bibliográfico e das reuniões que promoviam o debate sobre tal bibliografia, pôde-se notar que as informações obtidas de áreas como da cinesiologia e biomecânica auxiliam, de maneira decisiva, no aprimoramento do estudo pianístico do pesquisador. Fatores como intervalos entre períodos de prática ao instrumento, força aplicada ao teclado e maneiras de construção dos diferentes tipos de toque são reflexões que devem incorporar-se, cada vez mais, aos hábitos de estudo do pianista. A prática randômica, por exemplo, tem mostrado eficiência nos estudos de obras musicais. Dividir a obra em partes e alternar o estudo de cada uma destas partes favorece uma atenção concentrada na atividade proposta.

A "economia" de movimentos no desempenho pianístico deve ser uma busca constante do musicista. Tornar simples e naturais a movimentação do corpo durante a prática instrumental é fundamental na obtenção de agilidade e relaxamento muscular. A atividade ao piano, repetitiva em muitos aspectos, pode ser prejudicial ao pianista que não dedica a devida atenção à qualidade dos movimentos que realiza.

A fundamentação científica dos conhecimentos musicais e a busca pela cooperação interdisciplinar fazem com que o conhecimento seja cada vez mais enriquecido e expandido. Este estudo mostrou vários caminhos de investigação, evidenciando que pesquisas nesse sentido devem ter continuidade, buscando sempre a otimização do estudo e do desempenho músico-intrumental. 


\section{REFERÊNCIAS BIBLIOGRÁFICAS}

BARELLA, José A. Aquisição de habilidades motoras: do inexperiente ao habilidoso. Motriz, Rio Claro - SP, v.5, n.1, p.53-57, junho, 1999.

CORRÊA, U.C.; PELEGRINI, A.M. Interferência contextual em função do número de variáveis. Revista Paulista de Educação Física, v.10, n.1, p.21-33, 1996.

GALLAHUE, David L. A classificação das habilidades de movimento: um caso para modelos multidimensionais. Revista da Educação Física /UEM, Maringá, v.13, n.2, p.105-111, 2º . sem, 2002.

MAGILL, Richard. Aprendizagem Motora: conceitos e Aplicações. São Paulo: Edgard Blücher, 2000.

PÓVOAS, Maria B. C.. Ação pianística, desempenho e controle do movimento - uma perspectiva interdisciplinar. In: Anais do III Simpósio de Cognição e Artes Musicais. Salvador: EDUFBA, 2007. p 540-548.

RICHERME, Cláudio. Técnica pianística: uma abordagem científica. São João da Boa Vista, SP: AIR Musical Editora, 1996.

SCHMIDT, Richard A.; WRISBERG, Craig A. Aprendizagem e performance motora: uma abordagem da aprendizagem baseada no problema. 2. ed. Porto Alegre: Artmed, 2001.

SHEA, J.B.; GRAF, R.C. A model for contextual interference effects in motor learning. In: REYNOLDS, C. R. Cognitive Assessment: A multidisciplinary perspective. New York: Plenum Press, p. 73-87, 1994.

SHEA, J.B.; MORGAN, R.L. Contextual interference effects on the acquisition, retention and transfer of a motor skill. Journal of Experimental Psychology: Human Learning and Memory, v.5, n.2, p.179-87, 1979.

TEIXEIRA, L. A. Aprendizagem de habilidades motoras na ginástica artística. In: Nunomura, M. \& Nista-Piccolo.V.L. Compreendendo a ginástica artística. São Paulo, Phorte. p.77106, 2004. 